\title{
Elaboration and Characterization of a Hybrid Composite Material with Two Particles of the Same Size: Coco Shells and Palm Shells
}

\author{
Pierre Marcel Anicet Noah ${ }^{1,2 *}$, Ebanda Fabien Betene ${ }^{1,2}$, Suzie Viviane Obame ${ }^{1,2}$, \\ Beassoum Allasra ${ }^{2}$, Martin Christian Bindjeme ${ }^{2}$, Ateba Atangana ${ }^{1,2}$ \\ ${ }^{1}$ Laboratory of Mechanics, ENSET, University of Douala, Douala, Cameroon \\ ${ }^{2}$ Department of Mechanical Engineering, ENSET, University of Douala, Douala, Cameroon \\ Email: ^pierre.noah@ensetdouala.net
}

How to cite this paper: Noah, P.M.A., Betene, E.F., Obame, S.V., Allasra, B., Bindjeme, M.C. and Atangana, A. (2020) Elaboration and Characterization of a Hybrid Composite Material with Two Particles of the Same Size: Coco Shells and Palm Shells. Open Journal of Composite Materials, 10, 77-91.

https://doi.org/10.4236/ojcm.2020.104006

Received: July 1, 2020

Accepted: August 7, 2020

Published: August 10, 2020

Copyright $\odot 2020$ by author(s) and Scientific Research Publishing Inc. This work is licensed under the Creative Commons Attribution International License (CC BY 4.0).

http://creativecommons.org/licenses/by/4.0/ (c) (i) Open Access

\begin{abstract}
This work aims to develop and characterize a hybrid composite material with two particles of the same size. As reinforcing particles, the hulls of palm nuts and coconut are chosen. Hybrid composite material composites in the form of specimens were produced by molding at $10 \%, 20 \%$ and $30 \%$ mass fractions in various sizes $(0.63 \mathrm{~mm}, 1.25 \mathrm{~mm}$ and $2.5 \mathrm{~mm})$. The samples were physically characterized (water absorption rate, moisture content, actual, theoretical and apparent density) and mechanical in 3-point flexion. The main results are: the highest and minimum water absorption rate are respectively $3.57 \%$ and $0.67 \%$ for respectively particle sizes $1.25 \mathrm{~mm}$ (sample P10C30) and $0.67 \%$ in the size of $0.63 \mathrm{~mm}$ (sample P10C10). The moisture content varies from 0.64 to $7.14 \%$ respectively for the P20C20 $(2.5 \mathrm{~mm})$ and P10C30 $(2.5 \mathrm{~mm})$ samples. The maximum and minimum real density are $1340,518 \mathrm{Kg} / \mathrm{m}^{3}$ and $1055.981 \mathrm{Kg} / \mathrm{m}^{3}$, for respectively the composites of particles sizes $1.25 \mathrm{~mm}$ (P20C10) and $0.63 \mathrm{~mm}$ (sample P20C20). The minimum real density is its maximum theoretical density is $1194.949 \mathrm{Kg} / \mathrm{m}^{3}$ (for samples P20C10, P10C10 and P30C10); however, the minimum is $1189.966 \mathrm{Kg} / \mathrm{m}^{3}$ (P10C20 and P20C20). The bulk density varies from $933.28 \mathrm{Kg} / \mathrm{m}^{3}$ to $1176.1 \mathrm{Kg} / \mathrm{m}^{3}$, respectively, in sizes from $2.5 \mathrm{~mm}$ (P10C30) to $0.63 \mathrm{~mm}$ (for P10C30). As for the mechanical characteristics, the Modulus of Elasticity (MOE) varies from 25.664 GPa to $25.759 \mathrm{GPa}$, respectively, the samples P10C10 $(1.25 \mathrm{~mm})$ and P10C20 $(2.5 \mathrm{~mm})$. The MOE values describe a parabola whose peak is reached when the palm shell loads are $20 \%$, that is to say P20C10, whatever the particle size distribution. In resilience, samples with small particles are more resilient with a maximum value of $22.49 \mathrm{~J} / \mathrm{cm}^{2}$ and a minimum value of $4.45 \mathrm{~J} / \mathrm{cm}^{2}$ to verify the principles of Hall-Petch's law.
\end{abstract}




\section{Keywords}

Composite, Hybrid, Young's Modulus, Polyester, Particles, Hulls of Palm Nuts, Hulls of Coconut

\section{Introduction}

Modern technology (aerospace, aeronautics, naval, etc.) increasingly requires severe mechanical characteristics. New perspectives have appeared with the advent of composite materials, the field of use of which is constantly expanding to meet a certain number of criteria, namely: lightness, great rigidity, ease of implementation, etc. The reinforced composite material is a subgroup of the composite material class, which is one of the four engineering material classes (metals, polymers, ceramics, and composites) [1]. The composite material is defined as multiphase material composed of two or more constituents, with distinct boundary and different properties, combined together to optimize one or more specific properties [2]-[7]. The reinforced composite material is composed of a reinforcing phase embedded in continuous matrix phase. The matrix fixes the reinforcement in position, transfers and distributes the loads between the reinforcing components by the shear adhesion forces, and preserves the reinforcement from the external environment conditions.

Hybrid composites consist of two or several types of reinforcements. The general use of hybrid composites has increased because of their enhanced mechanical properties [8], thermal stability, and durability [9]. The use of recycled fillers as reinforcements from renewable sources has been also considered, with the aim of producing alternative materials addressing concerns related to the low sustainability of conventionally reinforced polymer composites [10]. Bleay and Humbertone [11] showed that: the hybrid composites could be produced with high levels of resistance, modulus, and damage tolerance, combined. Hybridization has been explored as a way to produce more cost-effective composites. Recent work in this area [12] [13] has studied hybrids containing two types of cheaper and less efficient reinforcements individually in place. Potential savings of $12 \%-17 \%$ have been identified through the use of hybridization. Hybrid composites showed better impact strength and other mechanical properties [14]-[19].

Compared to traditional materials, local hybrid composite materials (fibers and/or particles) are the object of the desire of many users. In Cameroon and Central Africa, it is noted that the coconut palm and the oil palm occupy large areas of exploitation. However, the hulls resulting from the post-consumption of nuts are undervalued by the populations despite their great hardness. The literature mentions studies of the strengthening of composites by coconut shells [20] [21].

The dimensional stability of materials is subject to changes in dimensional factors including length, thickness, and width as they are exposed to different conditions and environment such as humidity and dry and wet conditions. This 
is important for determining the shelf life, application, and end product for hybrid composites. To do so, different characterizations were conducted to investigate dimensional stability, such as thickness swelling, water absorption, density, and weathering and cyclic tests [22] [23] [24] [25] [26].

In this article, we study the development and characterization of a hydrous composite material with a polyester matrix reinforced by the charges of identical particle sizes, coconut, and palm nut shells. The same size particles can favor the development of homogeneous samples with optimal properties, because the porosity rate will be lower than for samples reinforced with particles of different sizes. To carry out this work we will first present the introduction, which will be followed by the materials and methodology relating to our study. Then, we will finish with the results, their interpretations, and the conclusion.

\section{Materials}

\section{Cocos Nuciferas}

Fruit picking took place in the city of Edea, in the coastal region of Cameroon. We have, thanks to a machete, made a separation between the coconut palm and its fruit. This is made more explicit in Figure 1 below.

The steps to obtain the coconut particles necessary for the formulation of the composite are presented in Figure 2 below, showing the process for obtaining coconuts.

The process for obtaining the coconut particles is shown in Figure 2 below.

Crushing is carried out using a mass to crumble the hulls. The shells are crushed using a shredder. The separation (sieving) of the particles allows us to obtain particles of grain size $0.63 \mathrm{~mm}, 1.25 \mathrm{~mm}, 2.5 \mathrm{~mm}$. Drying expels moisture from the particles. It is carried out using calibrated sieves (Figure 3 ).

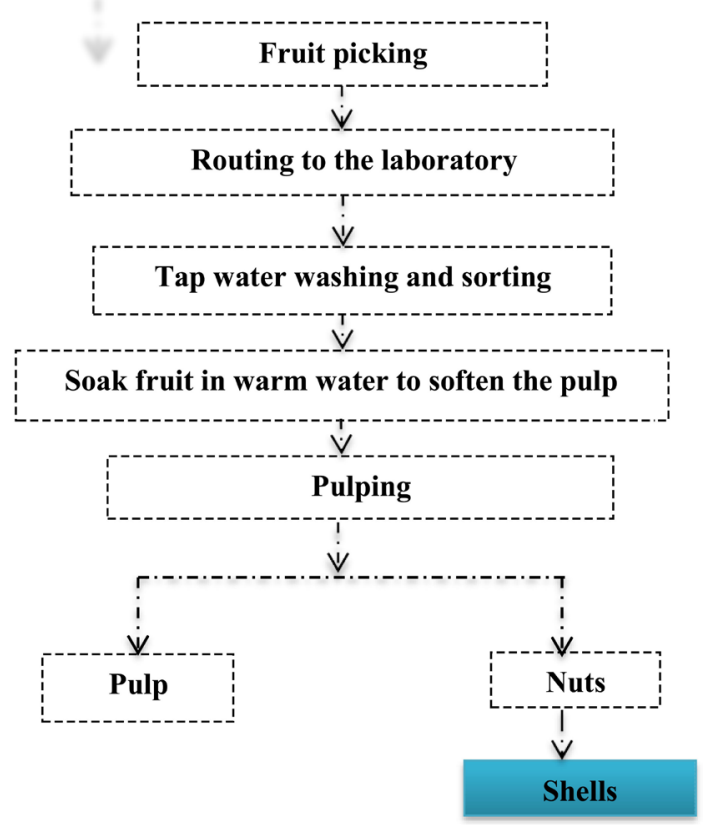

Figure 1. Process for obtaining coconuts. 


\section{Elaeis Guineensis wild variety}

Palm kernel hulls undergo the same stages (crushing, grinding, separation and drying) of transformation as coconut hulls, and they allow us as before to obtain particles of grain size $0.63 \mathrm{~mm}, 1.25 \mathrm{~mm}, 2.5 \mathrm{~mm}$.

The process for obtaining palm nuts is given in Figure 4.

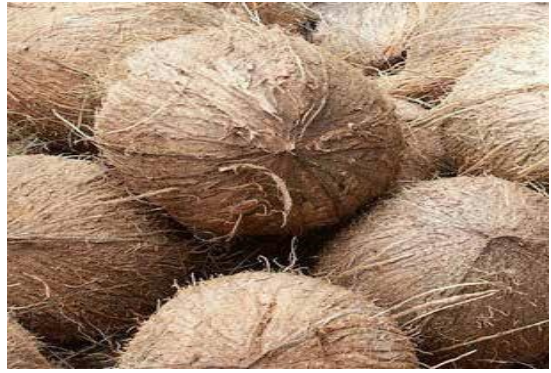

(a)

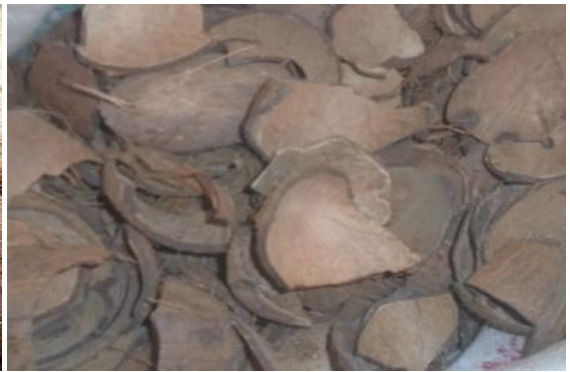

(b)

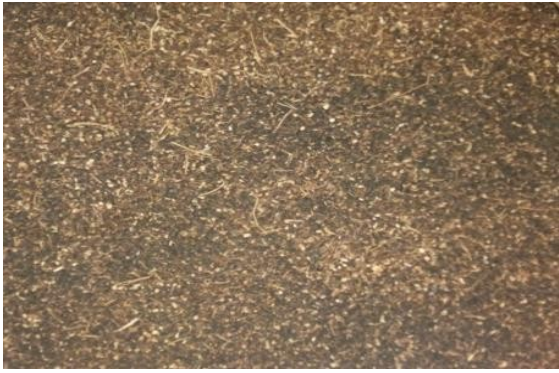

(c)

Figure 2. Process for obtaining coconut particles. (a) Coconut; (b) Coconut shells; (c) Crushed and sifted hulls.

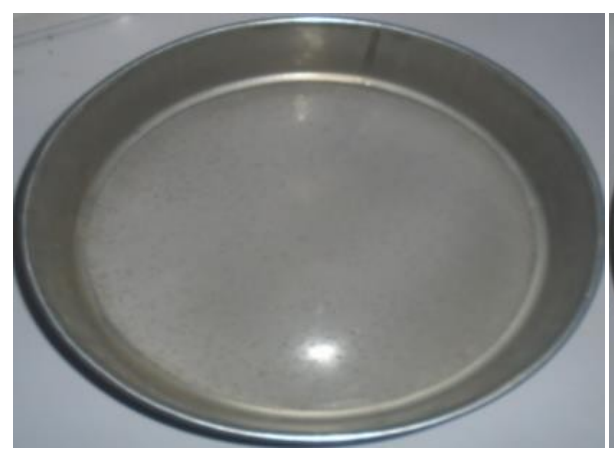

(a)

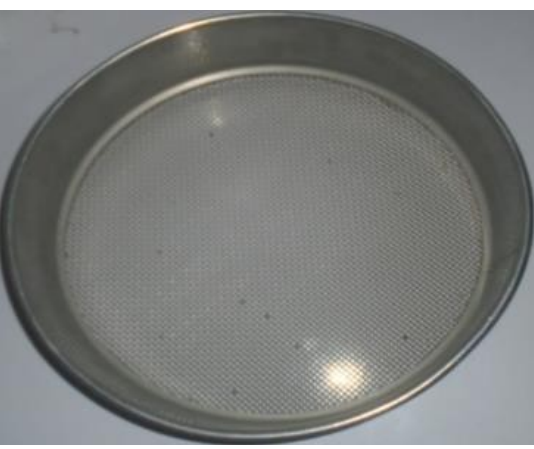

(b)

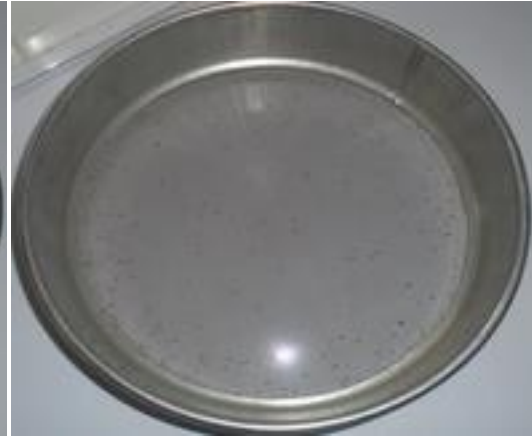

(c)

Figure 3. Figures (a) (sieve of $0.63 \mathrm{~mm}$ ), (b) (sieve of $1.25 \mathrm{~mm}$ ) and (c) (sieve of $2.5 \mathrm{~mm}$ ) respectively designate the standard sieves.

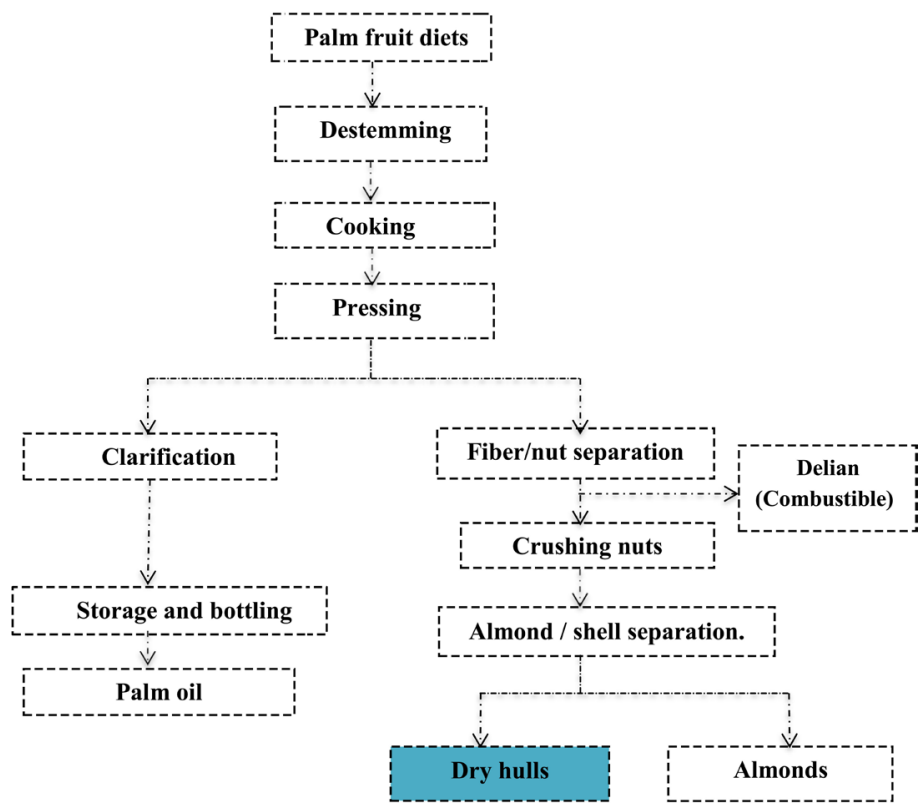

Figure 4. Process for obtaining palm nuts. 
Figure 5 shows the different stages of obtaining palm nut particles.

\section{Polyester Matrix}

Polyesters are synthetic thermosetting polymers that harden through the combination of an accelerator and a catalyst. Its characteristics are grouped in Table 1 below.

\section{Methods}

\section{Shaping and machining of test pieces}

In order to characterize the hybrid composite, it is necessary to shape it and machine it to standardized dimensions. To do this, it is important to respect the following steps (Figure 6).

At the end of this process, we obtained the test pieces having the following standardized dimensions: $150 * 15 * 7$ (according to standard BSI 2782) for the three-point bending test and $55 * 7.5 * 10$ (according to standard EN 10045) for the resilience test.

\section{Humidity rate}

To determine the humidity, we weigh the different samples and note the masses $m_{i 0}$. Then introduce the different samples in a microwave oven, then set the clock to 15 minutes and the operating temperature to $50^{\circ} \mathrm{C}$. After removing the sample, weigh it again, and read the mass. This process is repeated until the mass $m_{f}$ of the samples no longer varies. The humidity level is determined

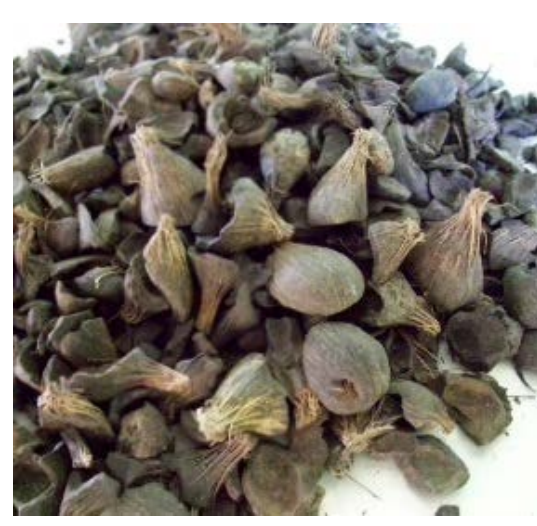

(a)

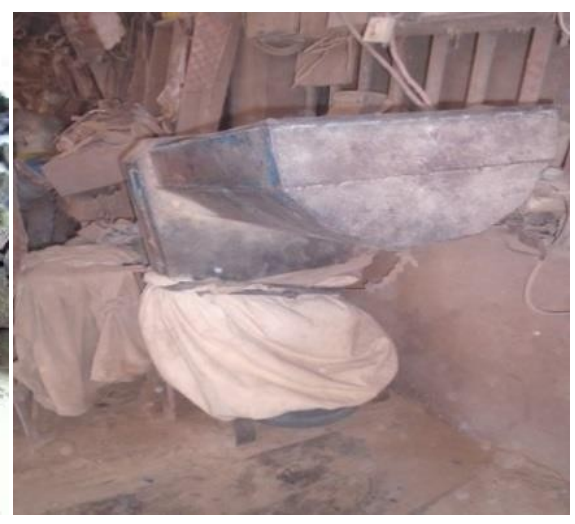

(b)

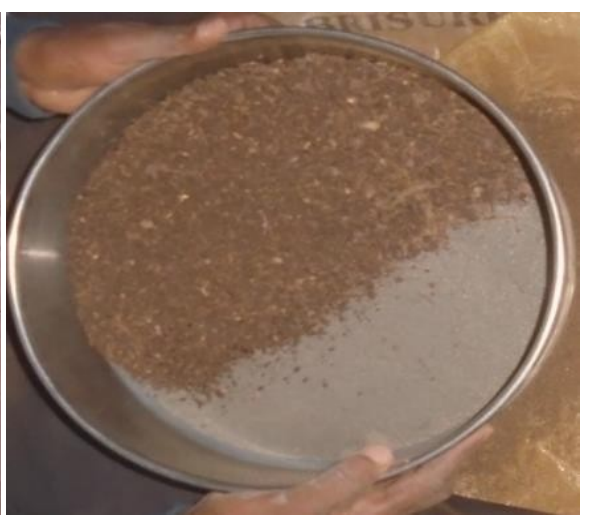

(c)

Figure 5. Some steps to get palm nut particles. (a) Palmist shell (b) Mulcher of palm kernels (c) Sieving of crushed palm shells.

Table 1. Characteristics of polyester (PE).

\begin{tabular}{cc}
\hline Characteristics & Values \\
\hline Volumic mass $\left(\mathrm{kg} / \mathrm{m}^{3}\right)$ & 1200 \\
Flexural modulus $(\mathrm{MPa})$ & $3000-4500$ \\
Stress at rupture in bending $(\mathrm{MPa})$ & $90-130$ \\
Elongation at break in bending $(\%)$ & $7 \%-9 \%$ \\
Poisson coefficient & 0.4 \\
Bending temperature under load $\left({ }^{\circ} \mathrm{C}\right)$ & $60^{\circ} \mathrm{C}-100^{\circ} \mathrm{C}$ \\
\hline
\end{tabular}




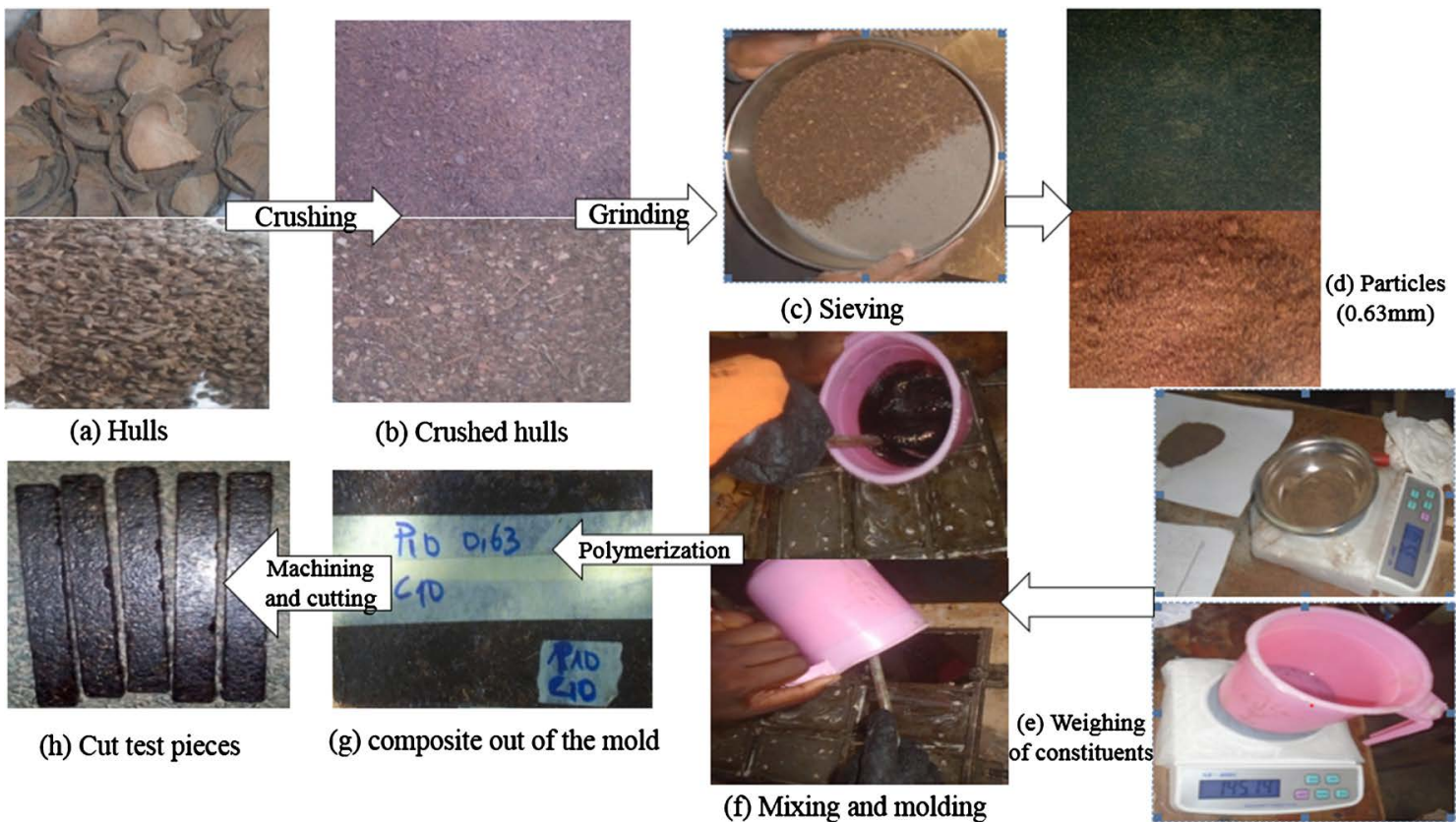

Figure 6. Steps in the manufacture of test pieces.

using the formula below:

$$
H(\%)=\frac{\left(m_{i o}-m_{f}\right)}{m_{i o}} \times 100
$$

\section{Volumic mass}

In order to obtain the density, the samples are placed in a microwave oven in order to extract all the humidity which they contain, and at a temperature of $50^{\circ} \mathrm{C}$. We then weigh the sample and record its mass $m_{s}$; The cylindrical beaker with inner radius $r$ is then filled to the height $h_{1}$ with water. The dry sample is placed in the beaker, and patiently waits for five minutes to promote absorption. We then measure the new height $h_{2}$ of water. The difference in level between $h_{1}$ and $h_{2}$ allows us to obtain the absolute volume of the sample. The absolute density is determined by the following formula:

$$
\rho_{a b s}=\frac{m_{s}}{\pi r^{2}\left(h_{2}-h_{1}\right)}
$$

\section{Absorption rate}

To determine the water absorption rate of the samples, according to British standard EN 317, they are dried in a microwave, in order to remove any moisture which they contain. We take a sample, weigh it, and note its mass $m_{h}$. The sample is then placed in water for 24 hours. Finally, we take the samples out of the water and measure the mass $m_{h}$.

$$
A b(\%)=\frac{m_{h}-m_{s}}{m_{s}} \times 100
$$

\section{Mechanical tests}

Figure 7 and Figure 8 show a Charpy pendulum sheep and a 3-point bending 


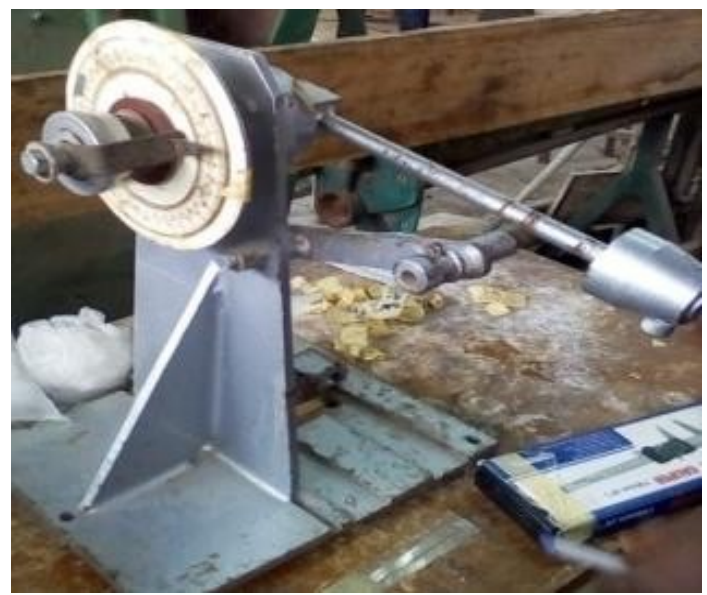

Figure 7. Charpy pendulum sheep.

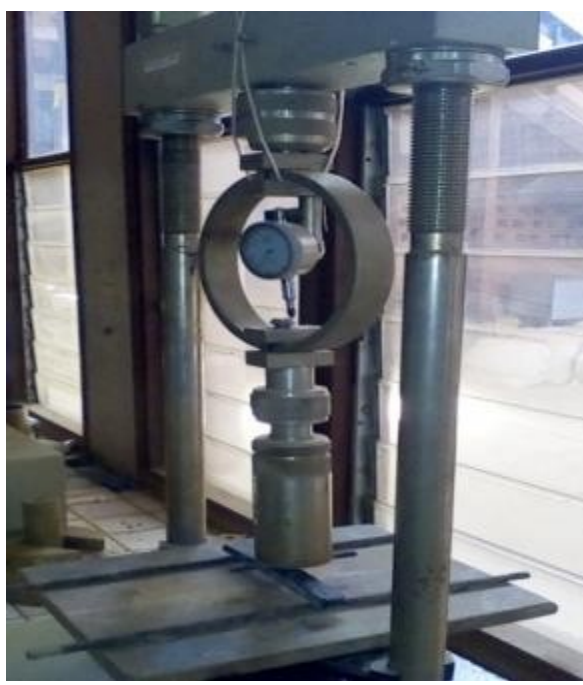

Figure 8. 3-point bending test machine.

test machine, respectively.

$$
K=\frac{m g l\left(\cos \theta_{r}-\cos \beta\right)}{S}
$$

$K$ : resilience in $\mathrm{J} / \mathrm{cm}^{2}$.

$\mathrm{m}$ : a hammer mass in $\mathrm{kg}$.

I: pendulum length in $\mathrm{m}$.

$\theta_{r}$ : angle of ascent of the hammer in degrees.

$\beta$ : free ascent angle of the pendulum in degrees.

$S$ : section of the notch specimen in $\mathrm{cm}^{2}$.

$$
M O E=\frac{\alpha L^{3}}{4 b e^{3}}
$$

$L$ : length of test piece in $\mathrm{mm}$.

$b$ : width of the test piece in $\mathrm{mm}$.

$e$ : thickness of test piece in $\mathrm{mm}$.

$\alpha$ : slope of the line $F=f(\delta)$ where. 
$\delta$ : arrow in the center of the test tube.

\section{Results and Discussions}

Let us consider the evolution of the Px/Cy samples, with $\mathrm{P}$ and $\mathrm{C}$, respectively, the palm kernel and coconut hulls and $\mathrm{x}$ and $\mathrm{y}$ designating their charge rates, respectively.

\section{Physical characterization}

Figure 9 shows the results of the physical tests.

The exploitation of the data relating to the evolution of the density (Figure 9(a)), makes it possible to note that, the real density is important for the samples P20/C10 (for all the granulometry) and for the sample P20/C20 $1.25 \mathrm{~mm}$ grain size. The peak $\left(1340.518 \mathrm{~kg} / \mathrm{m}^{3}\right)$ is reached with the P20/C10 sample with a grain size of $1.25 \mathrm{~mm}$. The P10/C10 sample is the most stable regardless of the particle size value. For this sample, the density of the composite does not vary as a function of the particle size. The lightest specimen is the P20/C20 for a grain size of $0.63 \mathrm{~mm}$ : it is the most optimal for applications where we want to reduce the size. The density is higher for the samples having a particle size of $1.25 \mathrm{~mm}$.

In the evolution of the water absorption rate (Figure $9(\mathrm{~b})$ ), we see that the $0 \%$ load sample does not absorb water: this is due to the fact that polyester is an impermeable material. The water absorption rate is maximum when the reinforcement rate is equal to $40 \%(\% \mathrm{x}+\% \mathrm{y})$, i.e. for samples $\mathrm{P} 10 / \mathrm{C} 30, \mathrm{P} 20 / \mathrm{C} 20$, $\mathrm{P} 30 / \mathrm{C} 10$. The $1.25 \mathrm{~mm}$ grain size samples (with a peak for P10/C30) absorb more water than the different grain size samples for identical reinforcements. In accordance with the literature, the absorption rate [27] is low when the charge rate is low $(20 \%)$, so therefore the smallest value $(0.671 \%)$ is obtained for the P10/C10 sample reinforced with fillers. with a grain size of $0.63 \mathrm{~mm}$. Samples with $1.25 \mathrm{~mm}$ particle size loads absorb more water than samples with different particle sizes.

The behavior of the coconut and palm kernel charges in the composite when faced with the water absorption test, and in order to check whether by swapping the reinforcement rates, the composite behaves in the same way, it emerges that for samples P10/C20 and P20/C10, it can be seen that when the composite is loaded with $10 \%$ palm kernel load and $20 \%$ coconut load, it has a higher absorption rate than that of samples loaded at $20 \%$ palm kernel hulls and $10 \%$ coconut hull except for loads of $1.25 \mathrm{~mm}$. As a result, the particles do not behave in the same way in the composite. In addition, we note that for reinforcement of $30 \%$ of load, it is optimal to load $20 \%$ of palm kernel and $10 \%$ of coconut, except when the particle size is $1.25 \mathrm{~mm}$. Knowing that the material is so faulty that it can absorb water, the P20/C10 formulation with a grain size of $1.25 \mathrm{~mm}$ is not recommended.

By analyzing the behavior of samples $\mathrm{P} 10 / \mathrm{C} 30$ and $\mathrm{P} 30 / \mathrm{C} 10$ (for the grain sizes $0.63 \mathrm{~mm}$ and $1.25 \mathrm{~mm}$ ), in order to check if by swapping the reinforcement rates, the composite behaves in the same way when facing the water. In both 

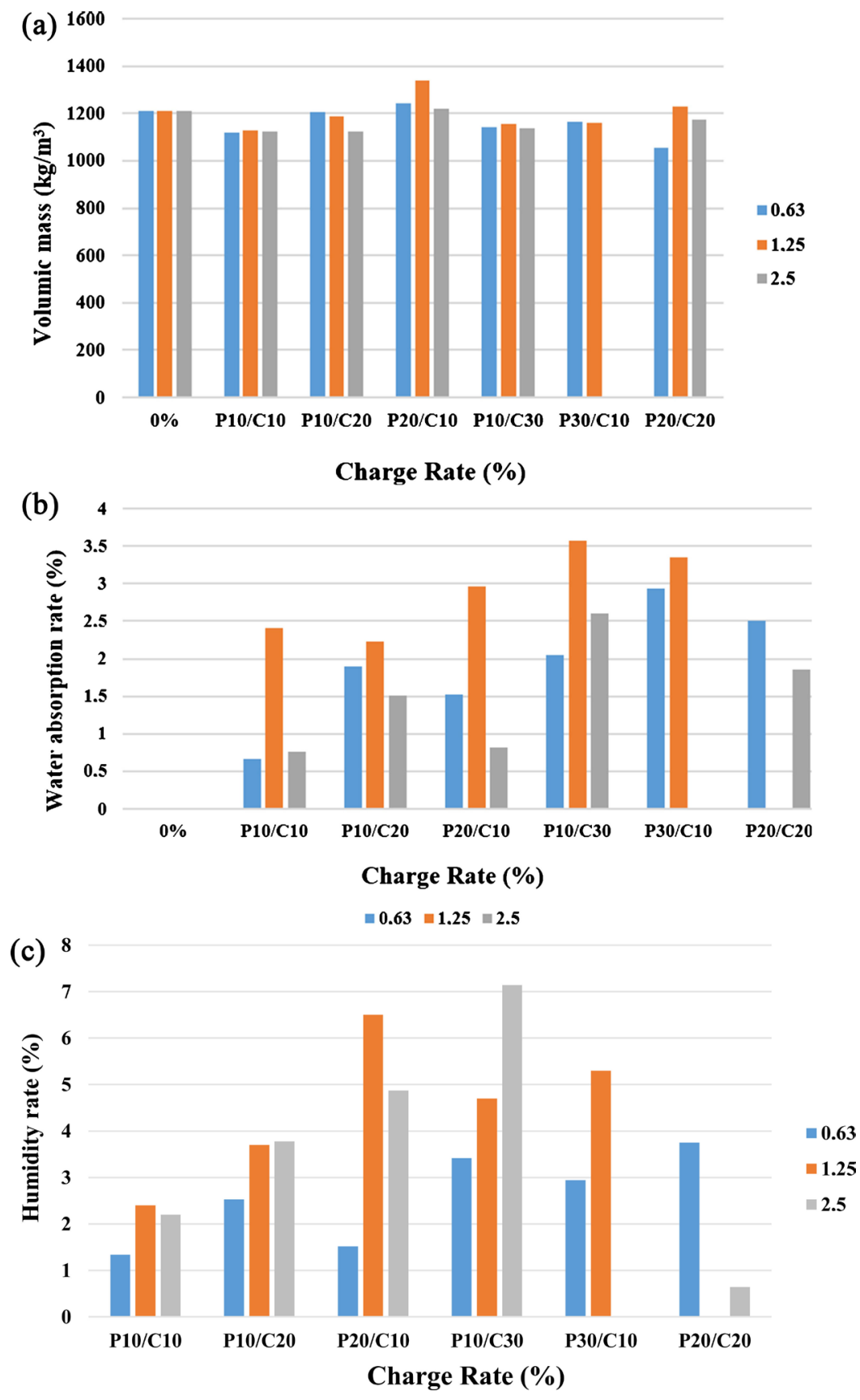

Figure 9. Physical test results: (a) Evolution of the real density of the different particle sizes as a function of the charge rate; (b) Water absorption rate of the composite; (c) Evolution of the humidity rate as a function of the load rate and the grain size.

cases, we find that the absorption rate is higher for particles with a particle size of $1.25 \mathrm{~mm}$, which shows us that the absorption rate is a function of the particle size. On the other hand, when we swap the reinforcements in the composite, we find that the absorption rate of the P10/C30 samples (between the grain size 0.63 $\mathrm{mm}$ and $1.25 \mathrm{~mm}$ ) is higher than that of the P30/C10 samples. In accordance with the literature [27], the previous results show that the rate of water absorption also depends on the nature of the reinforced fillers and their content. In an 
application where the absorption rate is decisive for the choice of material, these formulations with regard to their high water absorption rate are not recommended. In summary, this analysis shows that the absorption rate is a function of the charge rate, the nature of the charges, and the content of each input in the composite.

As for the evolution of the humidity rate Figure 9(c), we note that the humidity rate is generally high for large particles $(1.25 \mathrm{~mm}$ and $2.5 \mathrm{~mm})$. This phenomenon can be explained by the fact that their large sizes prevent the expulsion of moisture, embedded between the macromolecular chains of the biopolymer, during drying. The humidity level has the highest value for the $2.5 \mathrm{~mm}$ particle size P10/C30 sample. The humidity rate changes little when the reinforcement is weak (P10/C10 for example). This is justified by the fact that the polyester matrix is a material insensitive to moisture. What is paradoxical is that the P20/C20 sample with the lowest moisture content has not only a high load, but also particles of high particle size. This case undoubtedly represents a singularity for this study. The moisture content is lowest in formulations where the grain size is lowest. Which is recommended for most mechanical engineering applications. When there are more coconut loads than palm kernel loads (P10/C20 and P10/C30), the humidity increases with the particle size. Otherwise the evolution of the humidity rate has the shape of a parabola whose extremum is located at the top of the $1.25 \mathrm{~mm}$ grain size sample. This shows that the abundance of coconut charges compared to palm kernel charges maintains the evolution of the monotony of the evolution of the humidity rate. The humidity rate (according to the different particle sizes) varies very little for the P10/C20 formulations, compared to the P20/C10 formulations where the differences between the different particle sizes are high. In short, it emerges from this investigation that when the coconut load rate is higher than the palm kernel load rate, the evolution of the humidity rate increases with the particle size distribution, otherwise, the evolution of the humidity is parabolic with an extremum located on the $1.25 \mathrm{~mm}$ particle size sample.

\section{Mechanical characterization}

Figure 10 shows the results of the mechanical tests.

According to the evolutions, Figure 10(a) and Figure 10(b) of the Longitudinal elasticity module in 3-point bending (MOE), the behavior of palm kernel hulls, then coconut hulls in the composite was studied separately. It appears that, according to the evolution of the $\mathrm{MOE}$ for $\% \mathrm{P}=10 \%$ :

1) the MOEs for each particle size are maximum when the reinforcement is P10/C20;

2) the optimal value is obtained for the loading P10/C20 of particle size 2.5 $\mathrm{mm}$;

3) for each formulation, there is a parabolic evolution with an extremum on the formulations with a particle size of $1.25 \mathrm{~mm}$;

4) the formulations of identical particle size have a parabolic evolution with an 

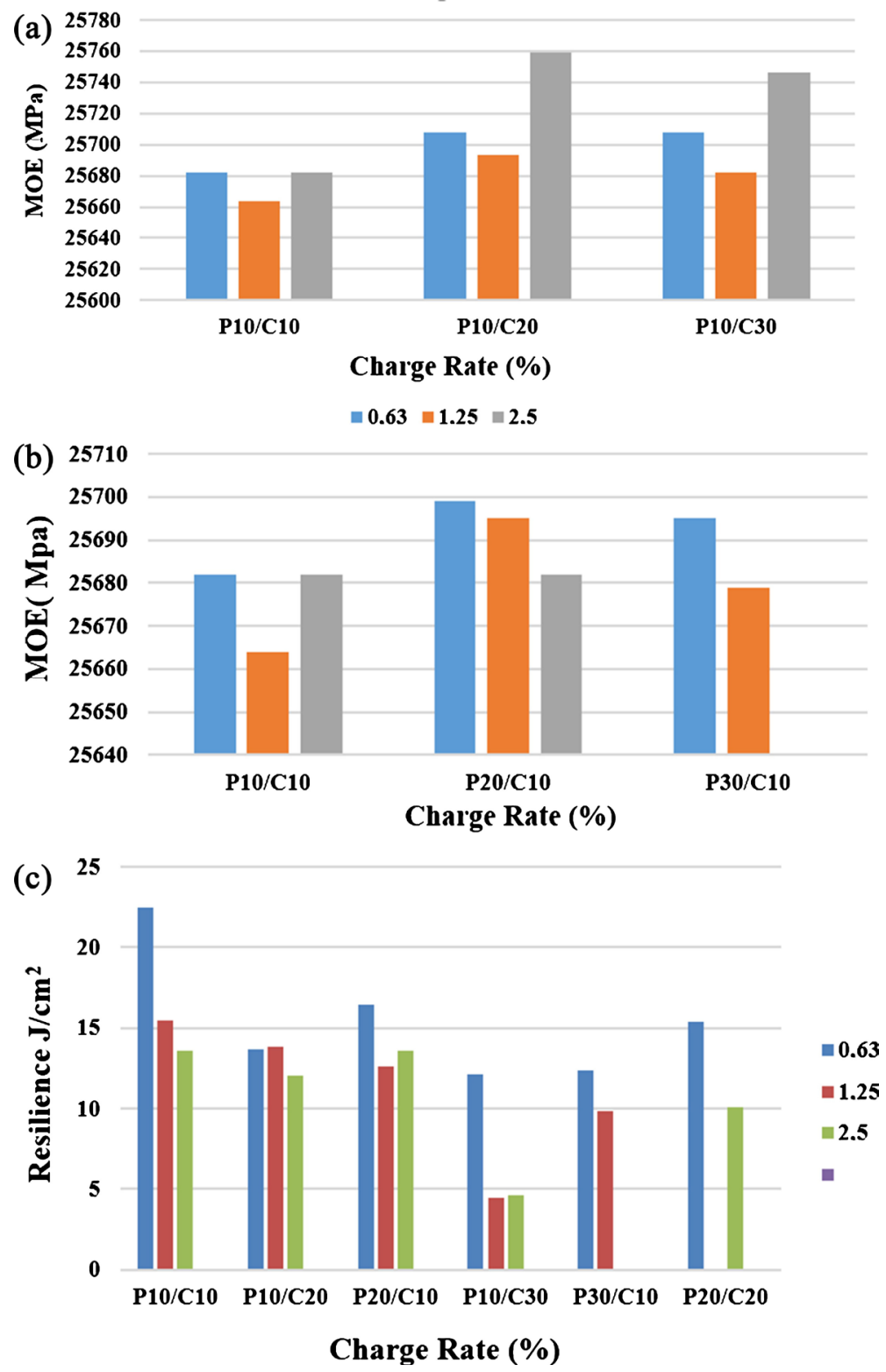

Figure 10. Results of mechanical tests: (a) MOE evolution for $\% \mathrm{P}=10 \%$; (b) MOE evolution for $\% \mathrm{C}=10 \%$; (c) Evolution of the resilience as a function of the particle size and the rate of reinforcement of the charges.

extremum for the formulations having a coconut content of $20 \%$.

These results show that the evolution of the MOE is a function of the charge rate and the particle size distribution, for a charge rate of fixed palm kernel. In addition, there is a regularity of the evolution for each formulation whether it is as a function of the granulometry or as a function of the rate of charge of coconut.

According to the evolution of the $\mathrm{MOE}$ for $\% \mathrm{C}=10 \%$, we observe that:

1) the MOEs for each particle size are maximum when the reinforcement is P20/C10;

2) the optimal value is obtained for the loading P20/C10 of grain size 0.63 $\mathrm{mm}$; 
3) for P20/C10 loads the MOE decreases when the particle size increases;

4) the evolution of the MOE as a function of the particle size is not the same for all formulations (parabolic at P10/C10 and monotonic at P20/C10);

5) the evolution of the $\mathrm{MOE}$ as a function of the palm kernel charge rate is parabolic (convex) for each particle size.

However, similarities between the two developments are observed. In fact, the MOEs for each particle size are maximum when the reinforcement is equal to $30 \%(\% \mathrm{x}+\% \mathrm{y})$. By fixing the particle size and the charge rate of one of the hulls, we note that the evolution of the MOE is parabolic (convex).

It is also observed divergences of the two evolutions. For $\% \mathrm{P}=10 \%$ the peak is obtained for the particle size of $2.5 \mathrm{~mm}$, while for $\% \mathrm{C}=10 \%$ the peak is obtained for the particle size of $0.63 \mathrm{~mm}$. On the other hand, unlike the first evolution where for a $30 \%$ reinforcement $(\mathrm{P} 10 / \mathrm{C} 20)$ the evolution is random, in the second evolution (P20/C10) the MOE decreases when the particle size increases.

In the evolution of resilience Figure 10(c) we find that:

The resilience is highest for loads with small particle sizes $(0.63 \mathrm{~mm})$, thus verifying Hall-Petch relationship which summarizes that the strength is inversely proportional to the particle size, the refinement of the particles created more grain boundaries that provided sufficient capacity to resist the applied stress [28] [29] [30].

For each particle size, the resilience is highest for the $\mathrm{P} 10 / \mathrm{C} 10$ formulation and the peak is reached for the P10/C10 sample with a grain size of $0.63 \mathrm{~mm}$. This result shows us that the material is highly resistant to shock when it is lightly loaded.

\section{Conclusion}

The aim of this article is to develop and characterize a hybrid composite material with two particles of the same size. In this investigation, we looked at hybrid composite materials reinforced with coconut hulls and palm nut hulls. The matrix used for the manufacture of this material is polyester which is very often used for the production of hybrid composite materials. Mechanical analysis allowed us to determine the MOE elasticity modulus by the 3 points flexion test, and to obtain the fracture energy by the resilience test which allowed us to verify the principles of Hall-Petch's law. The salient results of this study are: 1) the humidity is very high when the particles have a large particle size; 2) The water absorption rate of the test pieces is high when the reinforcement rate is high; 3 ) the density is overstated only for the P20/C10 samples; 4) the resilience is higher for the lowest charge rate $\mathrm{P} 10 / \mathrm{C} 10$ and for the lowest particle size $(0.63 \mathrm{~mm}) ; 5)$ the Modulus of Elasticity MOE is the highest when the reinforcement rate is equal to $30 \%$. The comparative MOE study found that the behavior of palm kernel hulls in the hybrid composite is different from that of coconut hulls. This observation makes it possible to obtain precise combinations and formulations which could prove decisive and profitable for specific applications. 


\section{Acknowledgements}

The authors of this article would like to thank the people of the city of Edea for their assistance in harvesting the coconut fruit. They also express their gratitude for the service rendered to the inhabitants of the city of Bandja by Bafang in the West region of Cameroon, who participated in the harvesting of palm nuts.

\section{Conflicts of Interest}

The authors declare no conflicts of interest regarding the publication of this paper.

\section{References}

[1] Ogin, S.L. (2000) Textile-Reinforced Composite Materials. In: Horrocks, A.R. and Anand, S.C., Eds., Handbook of Technical Textile, Woodhead Publishing Limited, London, 264-279. http://www.woodhead-publishing.com https://doi.org/10.1533/9781855738966.264

[2] Kaw, A. (2005) Mechanics of Composite Material. Taylor \& Francis Group, New York. https://doi.org/10.1201/9781420058291

[3] Peters, S.T. (1982) Handbook of Composites. Chapman \& Hall, Mountain View. https://fr.scribd.com/doc/114894789/Hb-Composites-2-Ed

[4] Gay, D. (1997) Matériaux Composites. Hermes, Paris. https://www.eyrolles.com/Sciences/Livre/materiaux-composites-9782866015862

[5] Cole, J.M. and Berthelot, J. (1999) Composite Materials: Mechanical Behavior and Structural Analysis. Springer-Verlag, New York.

https://www.amazon.com/Composite-Materials-Mechanical-Structural-Engineering $\underline{\text { /dp/0387984267 }}$

[6] Vasiliev, V.V. and Morozov, E.V. (2001) Mechanics and Analysis of Composite Materials. Elsevier Science Ltd., Oxford.

https://www.elsevier.com/books/mechanics-and-analysis-of-composite-materials/va siliev/978-0-08-042702-7

[7] Lucas, P. and Zanella, G. (2007) Mise en oeuvre des composites TP, Compounds à fibres courtes et longues. Techniques de l'ingénieur, Paris.

https://www.techniques-ingenieur.fr/base-documentaire/materiaux-th11/plasturgie -procedes-specifiques-aux-composites-42474210/mise-en-uvre-des-composites-tp-a $\underline{\mathrm{m} 5235 /}$

[8] Venkateshwaran, N., Elayaperumal, A. and Sathiya, G.K. (2012) Prediction of Tensile Properties of Hybrid-Natural Fiber Composites. Composites Part B: Engineering, 43, 793-796. https://doi.org/10.1016/j.compositesb.2011.08.023

[9] Yang, Y., Boom, R., Irion, B., Van Heerden, D.J., Kuiper, P. and De Wit, H. (2012) Recycling of Composite Materials. Chemical Engineering and Processing. Process Intensification, 51, 53-68. https://doi.org/10.1016/j.cep.2011.09.007

[10] La Mantia, F.P. and Morreale, M. (2011) Green Composites: A Brief Review. Composites Part A: Applied Science and Manufacturing, 42, 579-588. https://doi.org/10.1016/j.compositesa.2011.01.017

[11] Bleay, S.M. and Humbertone, L. (1999) Mécanical and Electrical Assessment of Hybrid Composites Containing Hollow Glass Reinforcement. Composites Sciences and Technology, 59, 1321-1329. https://doi.org/10.1016/S0266-3538(98)00170-5

[12] Curtis, P.T. and Browne, M. (1994) Cost Effective High Performance Composites. 
Composites, 25, 273-280. https://doi.org/10.1016/0010-4361(94)90219-4

[13] Hitchen, S.A. and Kemp, R.M.J. (1996) Development of Novel Cost Effective Hybrid Ply Carbon-Fibre Composites. Composite Science and Technology, 56, 1047-1054. https://doi.org/10.1016/0266-3538(96)00064-4

[14] Panneerdhass, R., Gnanavelbabu, A. and Rajkumar, K. (2014) Mechanical Properties of Luffa Fiber and Ground Nut Reinforced Epoxy Polymer Hybrid Composites. Procedia Engineering, 97, 2042-2051. https://doi.org/10.1016/j.proeng.2014.12.447

[15] John, K. and Naidu, S.V. (2004) Sisal Fiber/Glass Fiber Hybrid Composites: The Impact and Compressive Properties. Journal of Reinforced Plastics and Composites, 23, 1253-1258. https://doi.org/10.1177/0731684404035270

[16] KC, B., Faruk, O., Agnelli, J.A.M., Leao, A.L., Tjong, J. and Sain, M. (2015) Sisal-Glass Fiber Hybrid Biocomposite: Optimization of Injection Molding Parameters Using Taguchi Method for Reducing Shrinkage. Composites Part A, 83, 152-159. https://doi.org/10.1016/j.compositesa.2015.10.034

[17] Panthapulakkal, S. and Sain, M. (2007) Injection-Molded Short Hemp Fiber/Glass Fiber-Reinforced Polypropylene Hybrid Composites-Mechanical, Water Absorption and Thermal Properties. Journal of Applied Polymer Science, 103, 2432-2441. https://doi.org/10.1002/app.25486

[18] Swolfs, Y., Gorbatikh, L. and Verpoest, I. (2014) Fibre Hybridisation in Polymer Composites: A Review. Composites Part A, 67, 181-200.

https://doi.org/10.1016/j.compositesa.2014.08.027

[19] Shen, J., Min, X.Y., Huang, X., Zhou, S. and Ruan, D. (2012) Mechanical Properties of Luffa Sponge. Journal of the Mechanical Behavior of Biomedical Materials, 15, 141-152. https://doi.org/10.1016/j.jmbbm.2012.07.004

[20] Salmah, H., Romisuhani, A. and Akmal, H. (2013) Properties of Low-Density Polyethylene/Palm Kernel Shell Composites: Effect of Polyethylene Co-Acrylic Acid. Journal of Thermoplastic Composite Materials, 26, 3-15. https://doi.org/10.1177/0892705711417028

[21] Nimityongskul, P. and Daladar, T.U. (1995) Use of Coconut Husk Ash, Corn Cob Ash and Peanut Shell Ash as Cement Replacement. Journal of Ferrocement, 25, 35-44.

http://pascal-francis.inist.fr/vibad/index.php?action=getRecordDetail\&idt=3546009

[22] Shinoj, S., Panigrahi, S. and Visvanathan, R. (2010) Water Absorption Pattern and Dimensional Stability of Oil Palm Fiber Linear Low Density Polyethylene Composites. Journal of Applied Polymer Science, 117, 1064-1075. https://doi.org/10.1002/app.31765

[23] Law, T.T. and Zam, I. (2011) Water Absorption and Dimensional Stability of Short Kenaf Fiber-Filled Polypropylene Composites Treated with Maleated Polypropylene. Journal of Applied Polymer Science, 120, 563-572. https://doi.org/10.1002/app.33184

[24] Jawaid, M., Abdul Khalil, H.P.S., Noorunnisa Khanam, P. and Abu Bakar, A. (2011) Hybrid Composites Made from Oil Palm Empty Fruit Bunches/Jute Fibres: Water Absorption, Thickness Swelling and Density Behaviours. Journal of Polymers and the Environment, 19, 106-109. https://doi.org/10.1007/s10924-010-0203-2

[25] Osman, E.A., Vakhguelt, A., Sbarski, I. and Mutasher, S.A. (2012) Kenaf/Recycled Jute Natural Fibers Unsaturated Polyester Composites: Water Absorption/Dimensional Stability and Mechanical Properties. International Journal of Computational Materials Science and Engineering, 1, Article ID: 1250010. 
https://doi.org/10.1142/S2047684112500108

[26] Zafar, M.T., Maiti, S.N. and Ghosh, A.K. (2016) Effect of Surface Treatments of Jute Fibers on the Microstructural and Mechanical Responses of Poly(lactic acid)/Jute Fiber Biocomposites. RSC Advances, 6, 73373-73382.

https://doi.org/10.1039/C6RA17894D

[27] Mishra, D., Mohapatra, S. and Satapathy, A. (2019) A Comparative Study of Characterization and Water Absorption Behaviour of Polyester Composites with Inorganic and Organic Fibers. Materials Today: Proceedings, 19, 289-295.

[28] Daramola, O.O., Taiwo, A.S., Oladele, I.O., et al. (2020) Mechanical Properties of High Density Polyethylene Matrix Composites Reinforced with Chitosan Particles. Materials Today: Proceedings.

[29] Hall, E.O. (1951) The Deformation and Ageing of Mild Steel: III Discussion and Results. Proceedings of the Physical Society. Section B, 64, 747. https://doi.org/10.1088/0370-1301/64/9/303

[30] Petch, N.J. (1953) The Cleavage Strength of Polycrystals. Journal of the Iron and Steel Institute, 174, 25-28. 